\title{
End-Stage Renal Disease (ESRD): Physical Activity and Elucidation of Its Effects on Biochemical and Haematological Parameters in Haemodialysis Patients
}

\section{Muhammad S}

Renal Patient Support Group (RPSG), Royal Devon and Exeter (RD\&E) NHS Foundation Trust, England, UK

Corresponding author: Muhammad S, Royal Devon and Exeter (RD\&E) NHS Foundation Trust, England, UK, Tel: 44007968304769; E-mail: smuhammad1@nhs.net

Received: 28 June 2016; Accepted: 29 July 2016; Published: 2 August 2016

Citation: Muhammad S. End-Stage Renal Disease (ESRD): Physical Activity and Elucidation of its Effects on Biochemical \& Haematological Parameters in Haemodialysis Patients. Ann Clin Lab Res. 2016, 4: 3.

\section{Abstract}

End-stage renal disease (ESRD) is a progressive disorder for which there is no prospect of recovery, and for which patients receive regular haemodialysis. In ESRD the ability of the kidneys to excrete metabolic waste products and to regulate the composition of extracellular fluid is compromised. Symptoms of ESRD also include cardiovascular dysfunction, anaemia, malnutrition, muscle wasting, muscle weakness, glucose intolerance and reduced bone density. Patients with ESRD are likely to be challenged by participation in exercise whilst undergoing a HD regimen. Nevertheless there is a case for prescribing exercise in patients who struggle to become active. Some benefits of exercise In patients receiving haemodialysis, the benefits of physical exercise, which include: 1) Reduction of toxins and fluid overload in the circulatory system, permitting improved tolerance to the HD regimen and 2) Increased heart rate, which improves cardiovascular performance, 3) a reduction in comorbidities and an increase in well-being, and 4) the facilitation of positive coping strategies. An understanding how exercise can be of clinical advantage in ESRD patients is unique and challenging given the variety of nutritional and clinical conditions with which they present. The haematological and biochemical parameters which should be monitored in these patients (including blood potassium, urea, calcium and hemoglobin levels) need to be prioritized, and this prioritization depends in turn upon general patient well-being. More research is also required in the understanding of physiology and importance of good nutrition in this population. The aim of this work is to provide some background of the key parameters in HD patients and to identify literature on biochemical parameters which are affected during physical activity in HD patients. The results help to emphasize that closer attention should be paid to monitoring HD efficacy and $\mathrm{Kt} / \mathrm{V}$, a measure of dialysis adequacy.

Keywords: Nephrology; Physical activity; Haemodialysis; Chronic kidney disease; Kt/v

\section{Introduction}

Haemodialysis (HD) is a form of renal replacement therapy (RRT) as is continuous ambulatory peritoneal dialysis (CAPD). Although different in their protocols, both forms of treatment allow a steady-state of clinical biochemical and haematological parameters [1]. These include creatinine, urea, sodium, calcium, and other important components. It should be acknowledged; patients who have poor treatment efficacy (identified using Kt/V measurement) will feel worse over time. Physical activity may be an important factor in dialysis adequacy/efficiency (be it short-term or long-term) and in preparation for patients awaiting a transplant.

It is known that vigorous physical activity (particular intense cardiovascular workout) has many benefits. Some of the parameters that are affected include: $\beta$-endorphin, reduced urea, and positive psychology. These all benefit in the preparation to transplantation. However, at present there is little evidence that collaborates physical activity, stress and the parameters that are/should be monitored closely in the HD population; more efforts are being made to interrogate exercise literature (or physical activity research) and renal health. One study used two groups of athletes [1]. One of these groups represented subjects with a range of fitness levels from recreational to high-performance running. The second group represented canoeists with a similar range of fitness levels. The study measured the in vitro responses of leukocytes following acute anaerobic exercise over a $24 \mathrm{~h}$ recovery period. There was a reduction in proliferative lymphocyte response which was shown to be brief and transient. Other research investigating how physical activity effects specific immunological parameters demonstrated that prolonged endurance exercise causes an increase in plasma levels of interleukin-1 (II-1), possibly as a response to muscle injuries, but plasma interleukin-2 levels were generally reduced [2]. IL-1 secretion may enhance the responsiveness of peripheral blood mononuclear cells, but prostaglandin secretion decreases their IL-2 production. The observations may have been due to altered IL-2 levels or II-2 receptor expression. In this study, appropriately graded physical activity reduces the adverse immune reactions associated with challenging exercise. This study gives general information relating to lymphocyte migration during exercise [3]. Work has 
also informed how through the immune system, transplantation and psychological stress, some biochemical parameters are more affected than others [4].

\section{Aim of this Work}

This work aims to provide some background on key haematological and biochemical parameters which are measured in HD patients, and in addition to identify literature on biochemical parameters specifically influenced by physical activity in HD patients. I will conclude that closer attention to monitoring HD efficacy and $\mathrm{Kt} / \mathrm{V}$ is needed.

\section{General Benefits of Physical Activity in HD Patients}

It has been documented that physical activity as measured by peak oxygen uptake is generally low in HD patient groups [5-9]. There are a number of factors that may contribute to this, including anaemia, cardiac dysfunction (reduced contractility and increased preload and afterload of ventricular muscle), vascular dysfunction (a limitation in the capacity to divert cardiac output to skeletal muscle), skeletal muscle abnormalities (reduced fibre size, capillary density, mitochondrial density/function, increased diffusion distance) and/or metabolic abnormalities and autonomic nervous system dysfunction [10-17]. At the same time, physical activity has the following benefits in HD patients: Some benefits of exercise in HD patients include: 1) Reduces toxins in the blood and fluid overload, thus allowing patients to tolerate HD regimen better and 2) Exercise increases heart rate, which in turn also allows increases strength to cardiovascular system, 3) Because of the increased heart rate during exercise/physical activity, this will in turn allow an increase blood flow through vascular system (fistulae access, especially), which then means patients would get better Kt/V results overall, 4) Exercise will reduce the amount of fluid to come off during HD, 5) Exercise causes an increase in $\beta$-endorphin hormone, which causes a state of 'feeling good'-this in turn prompts a positive mental attitude despite overwhelming circumstances, 5) A long-term physical activity protocol (2-3 times a week) in HD patients may be one of the best ways for the body to prepare for a renal transplant [4]. Exhaustion post exercise generally causes a period where there is an activated immune response. This is not necessarily the same immune response as evident during a cold or an infection or even post transplantation. This is because during bouts of intense exercise, there is secretion of $\beta$ - endorphins and 6) Exercise can aid to cope with traumatic procedures such as fistulae and other forms of access creation [4].

\section{Physical Activity in Post-Transplant Patients}

Post-transplant CKD patients cannot participate in exercise to the same extend as in normal patients, and this is expected because they are at higher risk of cardiovascular disease [5-8]. Research suggests an association between higher physical activity levels and slower rate of estimated glomerular filtration rate (eGFR) loss in patients with CKD stages 3 and 4 [9]. Experimental interventions to improve cardiovascular risk factors or renal function by increasing exercise capacity in patients. In post-transplant patients, procedures and protocols differ from the HD patient. The most challenging period post-transplant is the initial 3-6 months, where the immune system is adapting/or tolerating the 'new' organ. For many patients this period is stressful and strenuous. The initial phases post-transplant involves 'constant' observation of creatinine (being the main clinical parameter); in addition to ensuring the immunosuppression dosage/titres are correct. A renal biopsy is quite common in early posttransplant and this brings on various additional emotions [4]. Exercise is recommended (but not prescribed) in the 'late' post-transplant period, where clinical chemistry parameters are less susceptible to 'blips'. Exercise generally improves coping, regardless of whether on an HD regime or transplanted. Patients who exercise 'later' post-transplant will also have reduced episodes of stress, depression and frustration. Physical activity may also indirectly aid to reduce episodes of AAR [4] because increase blood flow through afferent and efferent arterioles of the kidneys.

\section{Biochemical Parameters in HD Patients}

\section{Urea}

Urea is a small molecule produced from protein and it is excreted by the kidneys in normal renal function; when renal

function declines, urea levels rise $[16,18]$. It is synthesized by the reactions of the urea cycle from carbamoyl phosphate and ammonium ions, the latter being derived from deamination reactions $[16,18]$. It is not such an accurate test for kidney function as creatinine, but is a useful test when used together with creatinine, because it is affected by muscle breakdown, how much protein consumed and whether a patient has consumed enough fluid (it rises if dehydrated). The normal range $=2.5 \mathrm{mmol} / \mathrm{l}$ to $7.1 \mathrm{mmol} / \mathrm{l}(7-20 \mathrm{mg} / \mathrm{dl})[16,18]$.

\section{Potassium}

Potassium is important for cellular/interstitial fluid balance and for normal function of the heart, kidneys and other organs. A diet includes fruit (notably bananas), vegetables and protein provides the normal daily allowance of potassium. Potassium is also available in supplements, but the intake of too much potassium can be harmful, especially for people with renal disease or those taking some drugs to treat hypertension $[16,18]$. Potassium in is critical for maintaining the normal electrical rhythm of the heart and nerve impulses. The normal potassium level in the blood is $3.5 \mathrm{mEq} / \mathrm{L}$ to $5.0 \mathrm{mEq} / \mathrm{L}$ (milli Equivalents per liter). Potassium levels between $5.1 \mathrm{mEq} / \mathrm{L}$ to $6.0 \mathrm{mEq} / \mathrm{L}$ are considered to represent mild hyperkalemia $[16,18]$. 


\section{Calcium}

There is a broad normal physiological range of total and free Calcium concentrations, depending on age, sex, physiological state (e.g. pregnancy), combined with seasonal variations which follow a variation in the blood level of vitamin $D$, directly involved in the regulation of calcium concentration $[16,18]$. In HD patients, calcium and phosphate mineral metabolism is compromised owing to the attribute renal insufficiency and decline in renal function. The corrected total serum calcium concentration is normally $8.5 \mathrm{mg} / \mathrm{dL}$ to $10.2 \mathrm{mg} / \mathrm{dL}$, but there is no absolute reference point for serum calcium levels either in hypocalcemia or hypercalcemia, at which adverse symptoms will occur $[16,18]$. Table 1 provides a summary of clinical biochemical variables obtained from the UK Renal Registry (UKRR).

Table $1 \mathrm{~A}$ summary of clinical biochemical variables.

\begin{tabular}{|l|l|l|}
\hline \multicolumn{1}{|c|}{$\begin{array}{c}\text { Biochemical } \\
\text { Variable }\end{array}$} & Clinical Audit Measure & $\begin{array}{c}\text { Conversion Factor } \\
\text { from SI Units }\end{array}$ \\
\hline Phosphate & HD Patients: $1.1-1.7 \mathrm{mmol} / \mathrm{l}$ & \multirow{2}{*}{$\mathrm{Mg} / \mathrm{dl}=\mathrm{mmol} / \mathrm{l} \times 3.1$} \\
\cline { 2 - 3 } & PD Patients: $1.1-1.7 \mathrm{mmol} / \mathrm{l}$ & \\
\hline Calcium (adjusted) & Normal range $(<2.5 \mathrm{mmol} / \mathrm{l})$ & $\mathrm{Mg} / \mathrm{dl}=\mathrm{mmol} / \mathrm{l} \times 4$ \\
\hline $\begin{array}{l}\text { Parathyroid } \\
\text { hormone }\end{array}$ & $\begin{array}{l}2-9 \text { times upper limit of } \\
\text { normal }\end{array}$ & \multirow{2}{*}{$\mathrm{Mg} / \mathrm{dl}=\mathrm{mmol} / \mathrm{l} \times 9.5$} \\
\hline Bicarbonate & HD Patients: $18-24 \mathrm{mmol} / \mathrm{l}$ & \multirow{2}{*}{$\mathrm{Mg} / \mathrm{dl}=\mathrm{mmol} / \mathrm{l} \times 6.1$} \\
\cline { 2 - 2 } & PD Patients: $22-30 \mathrm{mmol} / \mathrm{l}$ & \multicolumn{1}{|c|}{} \\
\hline
\end{tabular}

Ref: Table adapted from [19]

\section{Relevance of Kt/V}

$\mathrm{Kt} / \mathrm{V}$ is used to measure the effectiveness of HD treatment, and involves the measurement of blood urea before and after treatment, to show how much toxin has been removed from the blood. URR is a simpler test of HD effectiveness: some units use URR, some use Kt/V, some use both. In the UK the accepted target for $\mathrm{Kt} / \mathrm{V}$ is a minimum of 1.2 , (the optimum target is between 1.6 and 1.8+) [18]. A slightly lower value may be acceptable if a patient has some renal function (eGFR $=15 \%$ + ). Lower values are associated with a poorer HD poorer prognosis. If $\mathrm{HD}$ patients exercise, the majority of clinical chemistry parameters will stay stable; this ultimately enhances HD efficiency [18]. Table 2 summarizes how patients can achieve higher Kt/V values.

It must be noted that not all patients will be able to achieve high $\mathrm{Kt} / \mathrm{V}$ results owing to pre-determined vascular complications.

\section{Importance of Creatinine in HD patients}

Effectively, creatinine is a by-product of muscle break-down. Because a majority of recipients on HD and CAPD do not have relative renal function, the creatinine will stay above the normal range $(60 \mathrm{mmol} / \mathrm{l}$ to $120 \mathrm{mmol} / \mathrm{l}$ or $0.7 \mathrm{mg} / \mathrm{dl}$ to 1.4 $\mathrm{mg} / \mathrm{dl})$. The creatinine will not necessarily be of significant difference when compared to a patient who has been transplanted, simply because regardless of HD efficacy, the quantity of blood processed/replenished is limited in comparison to the function of a native kidney/transplant. Creatinine is thus not specifically an important biomarker for renal function in HD patients; however it is important for muscle mass which is why protein is also important in these patients because it strengthens cardiac muscle and body mass [18].

Table 2 How patients can achieve higher Kt/V results.

\begin{tabular}{|l|}
\hline Increasing HD Efficiency \\
\hline Large gauge/Barrel needles post fistulae maturation \\
\hline 4.5 hours; 3 times a week \\
\hline Good spread of needles across access \\
\hline Increased dialysate flow (600 $\mathrm{mls} / \mathrm{min}$ to $700 \mathrm{mls} / \mathrm{min})$ \\
\hline Physical activity in between or during HD treatment \\
\hline Ref: Table adapted from [20] \\
\hline
\end{tabular}

\section{Haematological Parameters in HD Patients}

In ESRD, serum free iron concentration, and iron-saturation of transferrin, and ferritin are usually normal. Non-heme iron absorption from the gut is also normal. This has been observed in detailed studies on iron kinetics, where it has been proposed that, in view of the increased levels which can occur in response to acute anaemia or hypoxic hypoxia in ESRD patients, a decoupling between the endocrine and the excretory function of the kidney is responsible rather than its inability to produce erythropoietin [21].

The improvement in anaemia symptoms after starting haemodialysis was first described in 1970. It was postulated that this was due to the presence of the uremic inhibitors of erythropoiesis in the plasma. Polar lipids, arsenic, spermine and spermidine, vitamin $A$, and the parathyroid hormone are possible sources of uremic inhibition. Aluminium overload in haemodialysis patients is also proposed to cause microcytic anaemia, probably by inhibiting erythroid marrow as a result of binding to transferrin [22,23]. Blood loss, amounting to $4 \mathrm{ml}$ to $20 \mathrm{ml}$, is associated with the dialysis procedure, with additional loss resulting from frequent blood sampling. As a result a patient who is on dialysis may lose in excess of $2 \mathrm{mg}$ of iron per day. In addition, chronic infection and chronic inflammation may play a major role in the pathogenesis of anaemia [23]. One study has identified apparent microcytic hypochromic anaemia in HD patients [24] and another has revealed normocytic normochromic anaemia in $81 \%$ of $\mathrm{HD}$ patients [25]. The pathogenesis of uremic bleeding is not fully understood. No major alterations of the plasma coagulation factors have been reported, and the fibrinolytic system does not appear to be impaired. The common haematological 
manifestations of uremia are ecchymosis, purpura, epistaxis, and bleeding from venopuncture sites. Cardiac tamponade following pericarditis and pleural effusion can also occur. Spontaneous sub-capsular haematoma of the liver is a major complication, as are subdural haematomas. Uremic bleeding has also been attributed to a quantitative platelet reduction in $20 \%$ to $52 \%$ of the cases $[26,27]$. The exact mechanism behind the elevated erythrocyte sedimentation rate (ESR) in ESRD is not clear. Table 3 provides a summary of haematology in ESRD patients.

Table 3 A summary of haematological concerns in ESRD patients.

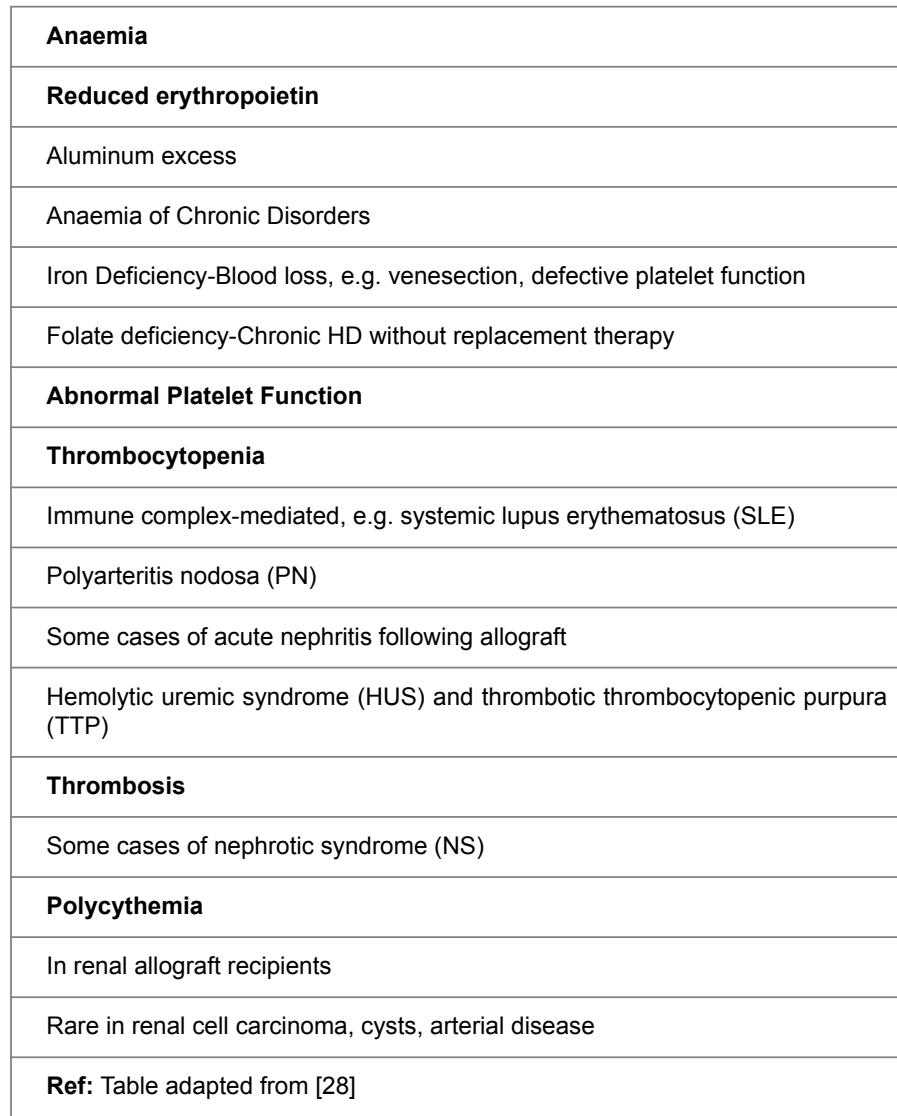

\section{Physical Activity in Renal Patients}

One study observed 18 HD patients, 12 continuous ambulatory peritoneal dialysis (CAPD) patients and 20 posttransplant patients performed maximal treadmill exercise tests. Heart rates and blood pressures were determined every minute and maximal oxygen consumption was measured directly [28]. Exercise capacity as measured by $\mathrm{VO}_{2}$ max is low in HD patients and is similar to inactive untreated renal transplant patients. Maximal heart rates were significantly lower in haemodialysis patients than transplant recipients. The lower exercise tolerance in end-stage renal disease (ESRD) indicates that most patients regardless of the treatment mode could benefit from attempts through exercise training to increase physical working capacity [29].

Another investigation explored the effects in uremic patients of handgrip exercise on plasma catecholamine levels,
neuropeptide-Y (NPY), and leu-enkephalin before and after HD [30]. In this study dopamine levels were higher in the uremic group before than after HD treatment both during rest 10.38 $\mathrm{pmol} / \mathrm{ml} \pm 0.39 \mathrm{pmol} / \mathrm{ml}$ and handgrip exercise $1.13 \mathrm{pmol} / \mathrm{ml} \pm$ $1.00 \mathrm{pmol} / \mathrm{ml}$ compared to controls $0.17 \mathrm{pmol} / \mathrm{ml} \pm 0.19$ $\mathrm{pmol} / \mathrm{ml}$, and $0.66 \mathrm{pmol} / \mathrm{ml} \pm 0.83 \mathrm{pmol} / \mathrm{ml})$. HD treatment led to further increase in dopamine $0.49 \mathrm{pmol} / \mathrm{ml} \pm 0.35 \mathrm{pmol} / \mathrm{ml}$ at rest. Noradrenaline levels were almost the same in uremic patients before $0.43 \mathrm{pmol} / \mathrm{ml} \pm 0.51 \mathrm{pmol} / \mathrm{ml}$ and after dialysis $0.46 \mathrm{pmol} / \mathrm{ml} \pm 0.60 \mathrm{pmol} / \mathrm{ml}$ as in control subjects 0.41 $\mathrm{pmol} / \mathrm{ml} \pm 0.37 \mathrm{pmol} / \mathrm{ml}$ during rest. The level measured after the handgrip was the highest in the uremic group after dialysis $2.10 \mathrm{pmol} / \mathrm{ml} \pm 2.00 \mathrm{pmol} / \mathrm{ml}$, significantly lower before dialysis $1.26 \mathrm{pmol} / \mathrm{ml} \pm 0.85 \mathrm{pmol} / \mathrm{ml}$, and the lowest in control group $0.78 \mathrm{pmol} / \mathrm{ml} \pm 0.43 \mathrm{pmol} / \mathrm{ml}$ [30]. Noradrenaline levels were very similar in the uremic group before dialysis $(1.54 \mathrm{pmol} / \mathrm{ml} \pm 1.05 \mathrm{pmol} / \mathrm{ml}$, after dialysis $1.79 \mathrm{pmol} / \mathrm{ml} \pm 1.29 \mathrm{pmol} / \mathrm{ml}$ and in the control group 1.46 $\mathrm{pmol} / \mathrm{ml} \pm 1.06 \mathrm{pmol} / \mathrm{ml}$ ) at rest. During the handgrip test its level was higher in uremic group after HD than before it (adequate values $8.78 \mathrm{pmol} / \mathrm{ml} \pm 4.61 \mathrm{pmol} / \mathrm{ml}$ and 6.70 $\mathrm{pmol} / \mathrm{ml} \pm 4.74 \mathrm{pmol} / \mathrm{ml}$ ). The difference between uremia group before dialysis and control group did not reach significance. The level of NPY has the tendency to increase in uremic patients. HD leads to following increase of its level, but the changes did not reach the significance both in rest and handgrip. Leu-enkephalin level was higher in uremic group $(9.21 \pm 7.62 \mathrm{pmol} / \mathrm{ml})$ compared to control group (5.22 \pm 1.53 $\mathrm{pmol} / \mathrm{ml})$. The team identified that there was a non-significant fall of this parameter post $\mathrm{HD}(6.79 \pm 4.76 \mathrm{pmol} / \mathrm{ml})$. This team established that uremia leads to increase the level of dopamine and Leu-enkephalin during rest and handgrip, but the level of epinephrine only during the handgrip. HD treatment led to further increase of dopamine during rest, but epinephrine, norepinephrine and Leu-enkephalin only during handgrip exercise [30].

\section{Physical Activity in CAPD Patients}

In a study on exercise tolerance, blood biochemistry, blood pressure (BP) control, cardiac function, and quality of life (QOL) over a 12-week exercise program [31], scores were calculated from 13 patients undergoing continuous ambulatory peritoneal dialysis (CAPD; six men and seven women of mean age, $46.5 \pm 12.8$ years, and with a mean duration of dialysis of $4.8 \pm 3.8$ years). The patients underwent exercise training using treadmill running or cycling with arm ergometers three times a week. Seven CAPD patients who were matched for age, sex, and duration on dialysis served as controls.

The mean peak aerobic capacity $\left(\mathrm{VO}_{2}\right.$ peak) of the patients increased by $16.2 \%$ after training (pre- and post-exercise, 17.2 $\pm 5.2 \mathrm{~mL} / \mathrm{kg} / \mathrm{min} \vee 20.0 \pm 6.4 \mathrm{~mL} / \mathrm{kg} / \mathrm{min} ; \mathrm{P}=0.004$ ) [31]. Although there were no significant changes in serum urea, creatinine, albumin, hematocrit levels, left ventricular diastolic/systolic diameter ratio and ejection fraction, an increasing trend in plasma high-density lipoproteins (HDLs) was observed (baseline vs. post exercise, $33 \pm 11 \mathrm{mg} / \mathrm{dL} \vee 40 \pm$ 
$14 \mathrm{mg} / \mathrm{dL} ; \mathrm{P}=0.06)$. Twenty four hour ambulatory BP monitoring indicated a significant increase in daytime systolic BP (pre- and post-exercise, $142 \pm 26 \mathrm{mmHg} \vee 157+/-22 \mathrm{mmHg}$; $\mathrm{P}=0.003)$, but no significant changes could be found in the ambulatory daytime diastolic $\mathrm{BP}$, nocturnal $\mathrm{BP}$, and resting clinic BP. The patients' QOL improved after training, with better scores in two of the kidney disease quality of life scales (KDQOL): burden of kidney disease and physical functioning. Two mild and uncomplicated hypotensive episodes were reported in two patients immediately after training. No changes occurred in exercise capacity, blood biochemistry, BP profile, and QOL scores in the controls. The team concludes that structured aerobic exercise is safe and can improve the exercise tolerance and QOL outcomes in CAPD patients [31]. Another study investigated factors that influence peak $\mathrm{VO}_{2}$ in patients receiving CAPD [32]. The study included 22 ESRD patients (12 men, 10 women; ages $29.64 \pm 8.29$ years; CAPD duration, 37.35 months \pm 7.15 months). The results suggested that low physical activity might be related to serum phosphorus levels, and that optimal control of serum phosphorus therapy would increase exercise capacity, duration, and oxygen consumption; resulting in a decrease of post-operative mortality in renal transplant candidates [32].

\section{Physical Activity in HD Patients}

In further work to determine the effects of physical activity on left ventricular function at rest and during sub maximal effort, thirty-eight ESRD patients maintained on HD were recruited and randomized into three groups [31]. Sixteen patients (Group A - mean age $46.4 \pm 13.9$ years, without clinical features of heart failure) participated in a 6 month renal rehabilitation program with supervised exercise consisting of three weekly sessions of aerobic training. A further ten patients (Group B - mean age $51.4 \pm 12.5$ years) followed a moderate exercise program at home. A final group of twelve (Group C - mean age $50.2 \pm 7.9$ years) were not trained and remained as controls. The level of anaemia and the HD prescription remained constant in all groups during the study [33]. A healthy control group comprised fifteen sex- and age-matched inactive individuals (Group D - mean age $46.9 \pm$ 6.4 years were the healthy controls. All patients at the start and end of the program underwent physical examination, laboratory tests, treadmill exercise testing, M-mode and 2-D echocardiograms performed at rest and at peak of supine bicycle exercise. Left ventricular volumes (EDV, ESV) and mass (LVM) were measured and ejection fraction (EF), stroke volume index (SVI) and cardiac output index (COI) were calculated using the standard formulae. The maximal oxygen consumption increased by $43 \%(P=0.001)$ and the exercise time by $33 \%(P=0.001)$ after training in group $A$, by $17 \%$ $(P=0.001)$ and $14 \%(P=0.01)$, respectively, in $B$, and both remained unchanged in Group C. Training in Group A was also associated with an increase in LVIDd (from $52.1 \pm 6.4 \mathrm{~mm}$ to $54.0 \pm 6.1 \mathrm{~mm}, \mathrm{P}=0.001)$ and $\operatorname{LVM}(226 \pm 67 \mathrm{~g}$ to $240 \pm 84 \mathrm{~g}$, $\mathrm{P}=0.05$ ) at rest with no change noted in Groups $B$ and $C$. Following a 6 month exercise training in Group $A$, an increase was also found in the resting EF by $5 \%=0.01$ ) and SVI by $14 \%$ $(P=0.001)$. There were no changes in these parameters in
Groups B and C [33]. Supine bicycle exercise after training in Group A was associated with an improvement in EF by $14 \%$ compared to the pre-training change $(P=0.001), S V I$ increased by $14 \%(P=0.001)$ and $\mathrm{COI}$ by $73 \%(P=0.001)$. There were similar but less pronounced changes from rest to sub maximal exercise in Group B following training at home. The untrained patients showed no changes in LV systolic function over the 6 month period. The study demonstrated that intense exercise training improves LV systolic function at rest in HD patients; both intense and moderate physical activity led to enhanced cardiac performance during supine sub maximal exercise [33].

Another study investigated when physical activity can reduce urea, creatinine, and potassium during HD [34]. Eleven patients (aged 32-78 years) on HD (4-58 months duration) were studied on paired HD sessions; one with exercise and the other as a control. Patients cycled for 5-20 min at sub maximal workload, and the exercise was followed by 10 min rest to achieve a total 60 min exercise period. Plasma concentrations of urea, creatinine and potassium were measured pre-, postand $30-\mathrm{min}$ post HD. The post-dialysis rebound (\% rebound) and reduction ratios (RR) of the solutes and equilibrated (twopool) urea and $\mathrm{Kt} / \mathrm{V}$ were calculated for comparison [34]. Results demonstrate rebounds of all three solutes were reduced following exercise. The rebound of urea decreased from $12.4 \%$ to $10.9 \%$ (median, $\mathrm{P}=0.01$; Wilcoxon signed rank test), creatinine from $21.2 \%$ to $17.2 \%(P=0.001)$ and potassium from $62 \%$ to $44 \%$ ( $P=0.05)$. Kt/V and RR increased significantly as a result: Kt/V urea from 1.00 to $1.15(P=0.001), R R$ urea from 0.63 to 0.68 ( $P=0.001) ; \mathrm{Kt} / \mathrm{V}$ creatinine from 0.71 to 0.84 $(P=0.01)$; and $R R$ creatinine from 0.51 to $0.57(P=0.05)$. From the results it was concluded that exercise increased the efficiency of HD by reducing the rebound of solutes due to increased perfusion of the skeletal muscle [34].

\section{Physical Activity and HD Adequacy}

A further study investigated the effect of exercise on HD adequacy [35]. Twenty (20) studies were performed in 20 maintenance HD patients. An adapted exercise cycle was attached to the dialysis bed. The patients in exercise group pedaled throughout dialysis, and had a 5-10 minutes rest if they needed, while the patients of a control group had no exercise. Blood, urea and nitrogen (BUN), serum creatinine $(\mathrm{SCr})$ and urea were measured just before and after $\mathrm{HD}$ immediately, and 60 minutes post HD. In the exercise group, after $\mathrm{HD}$, both BUN and $\mathrm{SCr}$ rates were shown to be significantly higher, whilst the rebound of $\mathrm{BUN}, \mathrm{SCr}$ and Urea were significantly lower than those in the control group $(\mathrm{P}<0.05$, approximately 0.01$)$. Kt/V was also higher in the exercise group $(P<0.05$, approximately 0.01$)$. The results showed that exercise during $\mathrm{HD}$ is a practical new way to improve the dialysis adequacy [35].

Physical training is being recommended as a complementary therapeutic approach [34]. This is supported by a study in which three methods of exercise training were evaluated in patients with ESRD: These were (1) a supervised outpatient programme that is held in a rehabilitation center; (2) a home exercise rehabilitation programme; and (3) an exercise 
rehabilitation programme undertaken during the first few hours of the HD treatment in a renal unit. Training data show that the application of an exercise training programme in patients with ESRD enhances their physical fitness. This improvement is due to central and mainly peripheral adaptations [36]. Physical activity training in HD patients increases aerobic capacity, causes favorable left ventricular functional adaptations, reduces blood pressure in patients with hypertension, modifies other coronary risk factors, increases the cardiac vagal activity and suppresses the incidence of cardiac arrhythmias. Moreover, physical training has beneficial effects on muscle structural and functional abnormalities [36]. The study established that central and peripheral adaptations to training cause an increase in their functional capacity and offer them a better chance of coping. Moreover, physical activity improves exercise tolerance of renal post-transplant patients [36].

\section{Physical Activity and Health Perception}

A further study investigated the effects of 2 methods of long-term physical training on physical fitness, perception of health and overall life situation in HD patients [37]. Forty eight HD patients who were free of any other systemic disease, and who each used two methods of exercise training for duration off our years, were studied. Half of the patients (Group A) were randomly assigned to a supervised outpatient exercise training program (three times weekly) on the non-HD days, whilst the other half (Group B) followed a training program with stationary bicycles during their HD sessions (3/weekly). The physical fitness and well-being parameters which were measured every year were: 1) aerobic capacity, as estimated from a modified treadmill exercise test and spiroergometric study, 2) the patients' perception of their health, 3) the overall life situation and 4) employment status [37]. During the study, there were 8 drop-outs in Group $A$ and 5 in B. No adverse effects of the exercise programs were reported. The one year of exercise training resulted in $38 \%$ in group $A$ (16 patients) and $31 \%$ in group $B$ (18 patients) improving their exercise time, a $47 \%$ increase in Group $A$ of peak oxygen consumption (VO2peak) and a $36 \%$ in group B by comparison to the baseline value [37]. After three additional years of training, significant improvements were also noted in exercise time (by $53 \%$ in Group A and by $43 \%$ in B) and VO2peak (by $70 \%$ in Group A and by $50 \%$ in Group B), as well as in other gas exchange variables in comparison to baseline values. However, the improvements in Group A were more pronounced than in B. Interestingly, the gains in exercise capacity were more enhanced in the first year of training in both groups. After four years of training, significantly more patients in both groups perceived their health and overall life situation as being improved compared to baseline. In addition, perception of improved health was higher in Group A. In conclusion, the study established that HD patients can adhere to long-term physical activity programmes on non-HD days, as well as during $\mathrm{HD}$ with considerable improvements in physical fitness and health [37].

\section{Diet and Nutrition}

HD patients have many concerns when it comes to eating the 'right food'. The diet of a HD patient is somewhat different to that of a patient post-transplant. Because the majority of $H D$ recipients do not have adequate renal function, this will cause some parameters to be unstable, particularly creatinine (relatively high), urea (high), phosphate (high, controlled with phosphate binders and potentially parathyroidectomy), and calcium (unstable, but controlled with calcium supplement/s). Potassium is also important to keep in control because at abnormal levels will cause hyperkalemia, causing arrhythmia. Potassium is reduced within the first hour of HD and this combined with muscle contraction will mildly effect calcium stores. As for urea and creatinine, these will not increase in patients who partake in exhaustive exercise because-physical activity should decrease these parameters [18].

Post exercise, it's sensible to take in carbohydrates, so the body is able to maintain energy; it is important that protein is part of a HD patient's normal diet because this allows strength building (muscle mass) [18]. Protein is an element in specific food (all types of fish, meat, and chicken).

Muscle mass tends to be reduced in the elder HD recipient, because the diet of an older patient will differ from younger patients. Exercise should decrease urea, decrease sodium, decrease potassium, increase appetite and potentially red cell/HB turnover with the aid of erythropoietin (EPO) prescription.

\section{Discussion}

The RRT patient will undergo various procedures and protocols; some being more traumatic than others. However, patients should challenge negative implications by being involved physical activity. Patients will not know how long they will be on either treatment forms and for this reason they should be encouraged (or prescribed) to get involved in fitness programmes, which has obvious benefits. The majority of literature in this article favors exercise for the dialysis patient because ultimately it can improve outlook. Exhaustive exercise does improve HD efficacy and ultimately it can aid in the run up and preparation for a renal transplant, but not all patients will be able to tolerate such advanced activity owing to longerterm effects of HD [38]. It seems obvious there are various ways that HD efficacy can be enhanced through physical activity $[39,40]$. Research has shown that physical activity increases the efficiency of HD by reducing tissue solute composition due to increased perfusion of the skeletal muscles [32]. Research has also identified that exercise during HD is a practicable new way to improve HD efficiency [33]. Though debatable, perhaps the counter argument to this is that patients should not exercise during HD because they may experience reduced oxygen as red cells are continuously being turned over and patients may become prone to cramping as a complication, which then leads to hypotensive episodes. Perhaps one of the main recommendations is thus to see that patients partake in physical activity before/in between their HD sessions or at least 2-4 hours before. In turn, patients will 
find that they feel better and ultimately find this improves treatment efficacy and urea clearance. Patients would also feel more energized if exercise is routine.

\section{Conclusion}

Physical activity as part of routine RRT has various benefits and it is evident that more research contributing to physical activity/exercise in renal patients is needed [41]. More research and studies are prompting discussion $[42,43]$. However, when exploring the larger role of physical activity in this patient population, it is important to inter-relate biochemical and haematological parameters, thus allowing a better picture of how blood and chemistry can improve in patients undergoing a HD regimen. There are limited studies exploring haematology parameters in HD patients who partake in physical activity and this may be due to general understanding that most HD patients have low hemoglobin levels. The immune system also plays a role. With most patients having co-morbidities, it would otherwise be good to see more research that associates physical activity with endocrinology in patients with ESRD, (i.e. to understand how HD patients' and their parameters are affected with psychological stress and $\beta$-endorphins). Certainly more longitudinal and cross-sectional studies are required to inform future care and practices.

\section{References}

1. Sietsema KE, Hiatt WR, Esler A, Adler S, Amato A, et al. (2002) Clinical and Demographic Predictors of Exercise Capacity in EndStage Renal Disease. Am J Kidney Dis 39: 76-85.

2. Fry RW, Morton AR, Keast D (1992) Acute intensive interval training and T-lymphocyte Function. Med Sci Sports Exerc 24: 339-45.

3. Shephard RJ, Rhind S, Shek PN (1994) Exercise and training: influences on cytotoxicity, interleukin-1, interleukin-2 and receptor structures. Int J Sports Med 3: 154-166.

4. Muhammad S (2015) The Immune System, Transplant Rejection and Psychological Stress, LAP Publishing (ISBN: 978-3-659-69166-9).

5. Perazella MA, Khan S (2006) Increased mortality in chronic kidney disease: a call to action. Am J Med Sci 331: 150-153.

6. Sarnak MJ, Levey AS, Schoolwerth AC, Coresh J, Culleton B, et al. (2003) Kidney disease as a risk factor for development of cardiovascular disease: a statement from the American Heart Association Councils on Kidney in Cardiovascular Disease, High Blood Pressure Research, Clinical Cardiology, and Epidemiology and Prevention. Circulation 108: 2154-2169.

7. Turin TC, Ahmed SB, Tonelli M, Manns B, Ravani P, et al. (2013) Proteinuria and life expectancy. Am J Kidney Dis 61: 646-648.

8. Myers J, Prakash M, Froelicher V, Do D, Partington S, et al. (2002) Exercise capacity and mortality among men referred for exercise testing. N Engl J Med 346: 793-801.

9. Culleton BF, Hemmelgarn BR (2003) Is chronic kidney disease cardiovascular disease risk factor? Semin Dial 16: 95-100.

10. O'Hare AM, Tawney K, Bacchetti P, Johansen KL (2003) Decreased survival among sedentary patients undergoing dialysis: results from the Dialysis Morbidity and Mortality Study Wave 2. Am J Kidney Dis 41: 447-454.

11. Padilla J, Krasnoff J, Da Silva M, Hsu CY, Frassetto L, et al. (2008) Physical functioning in patients with chronic kidney disease. $J$ Nephrol 21: 550-559.

12. Robinson-Cohen CL, Littman AJ, Duncan GE, Weiss NS, et al. (2014) Physical activity and change in estimated GFR among persons with CKD. J Am Soc Nephrol 25: 399-406.

13. Eidemak I, Haaber AB, Feldt-Rasmussen B, Kanstrup IL, Strandgaard $S$ (1997) Exercise training and the progression of chronic renal failure. Nephron 75: 36-40.

14. Gregory SM, Headley SA, Germain M, Flyvbjerg A, Frystyk J, et al. (2011) Lack of circulating bioactive and immunoreactive IGF-I changes despite improved fitness in chronic kidney disease patients following 48 weeks of physical training. Growth Horm IGF Res 1: 51-56.

15. Leehey DJ, Moinuddin I, Bast JP, Qureshi S, Jelinek CS, et al. (2009) Aerobic exercise in obese diabetic patients with chronic kidney disease: a randomized and controlled pilot study. Cardiovasc Diabetol 8: 62.

16. Howden EJ, Leano R, Petchey W, Coombes JS, Isbel NM, et al. (2013) Effects of exercise and lifestyle intervention on cardiovascular function in CKD. Clin J Am Soc Nephron 8: 1494-1501.

17. Headley S, Germain M, Milch C, Pescatello L, Coughlin MA, et al. (2012) Exercise training improves HR responses and VO2peak in predialysis kidney patients. Med Sci Sports Exerc 44: 2392-2399.

18. Johansen KL, Kaysen GA, Young BS, Hung AM, da Silva M, et al. (2003) Longitudinal study of nutritional status, body composition, and physical function in hemodialysis patients. Am J Clin Nutr 77: 842-846.

19. UK Renal Registry (UKRR) 17th Annual Report, Management of Biochemical Variables.

20. Muhammad S (2006) From personal/reflective notes.

21. Levey AS, Coresh J (2002) The National Kidney Foundation: the K/DOQI clinical practice guidelines for chronic kidney disease: evaluation, classification and stratification. Am J Kidney Dis 39: 66.

22. Lynn K (2005) Renal replacement treatment for end stage renal failure: The ideal scenario. Medicine Update 628-632.

23. Sakhuja V, Sud K (2003) End stage renal disease in India and Pakistan: the burden of the disease and the management issues. Kidney Int Suppl S83: 115-118.

24. Gedela SR, Varma PP, Baliga KV, Chawla ML, Rai R (2004) Renal replacement therapy: its status in India. Medicine Update 451-456.

25. Talwar VK, Gupta HL, Shashinarayan (2002) The clinicohaematological profile in chronic renal failure. J Assoc Physicians India 50: 228-233.

26. Callen IR, Limarzee LR (1950) Blood and bone marrow studies in renal disease. Am J Clin Pathol 20: 3-23.

27. Castaldi PA, Rozenberg MC, Stewart JH (1966) The bleeding disorder of uraemia: A qualitative platelet defect. Lancet 2: 66-69.

28. Hoffbrand AV, Pettit JE, Moss PAH (2001) Haematological Changes in Systemic Disease in Essential Haematology, Fourth Edition 293-294. 
29. Painter P, Messer-Rehak D, Hanson P, Zimmerman SW, Glass NR (1986) Exercise Capacity in Haemodialysis, CAPD, and Renal Transplant Patients. Nephron 42: 47-51.

30. Klin $M$, Waluga $M$, Rudka $R$, Madej $A$, Janiszewska $M$, et al. (1998) Plasma Catecholamines, Neuropeptide $Y$ and Leucine Enkephalin in Uraemic Patients before and after Dialysis during Rest and Handgrip. Boll Chim Farm 137: 306-313.

31. Lo CY, Li L, Lo WK, Chan ML, So E, et al. (1998) Benefits of Exercise Training in Patients on Continuous Ambulatory Peritoneal Dialysis. Am J Kidney Dis 32: 1011-1018.

32. Ulubay G, Akman B, Sezer S, Calik K, Eyuboglu Oner F, et al. (2006) Factors affecting Exercise Capacity in Renal Transplantation Candidates on Continuous Ambulatory Peritoneal Dialysis Therapy. Transplant Proc 38: 401-405.

33. Deligiannis A, Kouidi E, Tassoulas E, Gigis P, Tourkantonis A, et al. (1999) Cardiac Effects of Exercise Rehabilitation in Haemodialysis Patients. Int J Cardiol 70: 253-266.

34. Kong CH, Tattersall JE, Greenwood RN, Farrington K (1999) The Effect of Exercise during Haemodialysis on Solute Removal. Nephrol Dial Transplant 14: 2927-2931.

35. Sun Y, Chen B, Jia Q, Wang J (2002) The Effect of Exercise during Haemodialysis on Adequacy of Dialysis. Chinese J Med 41: 79-81.

36. Kouidi EJ (2001) Central and Peripheral Adaptations to Physical Training in Patients with End-Stage Renal Disease. J Sports Med 31: 651-665.
37. Kouidi E, Grekas D, Deligiannis A, Tourkantonis A (2004) Outcomes of Long-term Exercise Training in Dialysis Patients: Comparison of two Training Programs. J Clin Nephrol 1: 31-38.

38. Koufaki P, Mercer TH, Naish PF (2002) Effects of Exercise Training on Aerobic and Functional Capacity of End-Stage Renal Disease Patients. Clin Physiol Funct Imag 22: 115-124.

39. Koufaki P, Nash PF, Mercer TH (2002) Assessing the Efficacy of Exercise Training in Patients with Chronic Disease. Med Sci Sports Exercise 34: 1234-1241.

40. Painter $P$ (2008) Exercise in chronic disease: physiological research needed. Exerc Sport Sci Rev 36: 83-90.

41. Painter PL (1988) Exercise in End-Stage Renal Disease. Exerc Sport Sci Rev 16: 305-339.

42. Koufaki P, Greenwood SA, Macdougall IC, Mercer TH (2013) Exercise therapy in individuals with chronic kidney disease: a systematic review and synthesis of the research evidence. Annu Rev Nurs Res 31: 235-275.

43. Greenwood SA, Koufaki P, Rush R, Macdougall IC, Mercer TH (2014) British Renal Society Rehabilitation Network Exercise counselling practices for patients with chronic kidney disease in the UK: a renal multidisciplinary team perspective. Nephron Clin Pract 128: 67-72. 